\title{
Chitin Nanofiber Membranes for Chiral Separation
}

\author{
Yuuki Sueyoshi, Takeshi Hashimoto \& Masakazu Yoshikawa (Corresponding author) \\ Department of Biomolecular Engineering, Kyoto Institute of Technology \\ Matsugasaki, Kyoto 606-8585, Japan \\ Tel: 81-757-247-816_E-mail: masahiro@kit.ac.jp
}

Shinsuke Ifuku

Department of Chemistry and Biotechnology

Graduate School of Engineering, Tottori University

Koyama-cho Minami, Tottori 680-8522, Japan

Tel: 81-857-315-592Ｅ-mail: sifuku@chem.tottori-u.ac.jp

\author{
Received: September 9, 2011 \\ Accepted: September 28, $2011 \quad$ Published: February 1, 2012 \\ doi:10.5539/sar.v1n1p42 \\ URL: http://dx.doi.org/10.5539/sar.v1n1p42
}

\begin{abstract}
Nanofiber membranes for chiral separation were prepared from chitin, which is the most abundant natural amino polysaccharide. The membrane showed chiral separation ability by adopting concentration gradient as a driving force for membrane transport. In other words, the chitin nanofiber membrane selectively transported the D-isomer of glutamic acid (Glu), phenylalanine (Phe), and lysine (Lys) from the corresponding racemic amino acid mixtures.
\end{abstract}

Keywords: Chiral separation, Chitin, Membrane, Nanofiber membrane, Optical resolution

\section{Introduction}

L-Glutamic acid (L-Glu), which is usually used as a seasoning in Japan, is tasty, while the corresponding D-glutamic acid (D-Glu) gives a different taste. This is one of familiar examples. A lot of optically active compounds show different physiological activities, depending on their mirror image isomers (Voet et al., 1990; McKee et al., 2003). From this, the production of optically pure compounds is an important process in various industries, involving pharmaceuticals, agrochemicals, food additives, fragrances, and so forth. Asymmetric synthesis is thought to be an ultimate way to obtain enantiometrically pure compounds from a standpoint of green chemistry. However, the development of asymmetric synthesis is not so fast. Chiral separations, such as crystallization resolution, kinetic resolution, chromatographic separation, membrane-based separation and so forth, are still mighty and promising methods to obtain optically pure compounds. Among those chiral separation methods, membrane-based separation is ecologically and economically competitive to other chiral separation methods. Membrane-based separation is continuously operated under mild conditions and process scale-up is relatively easy. From above, membrane-based separation can be called "green separation technology" not only in chiral separation but also in separations of other mixtures. Membrane-based separation with separation membranes fabricated from green polymer will surely become a green separation technology.

The authors research group developed membranes from various naturally occurring or 'green polymers', their derivatives, and wastes from food industries as resources for membrane material so that we can construct sustainable environment and society. To this end, the authors' research group developed membranes from various raw materials, such as cellulose acetate for optical resolution (Izumi et al., 1997; Yoshikawa et al., 1999), egg shell membranes for chiral separation (Kondo et al., 2001), agarose for pervaporation (Yoshikawa et al., 2000, 2002), gelatin for vapor permeation (Yoshikawa et al., 2004a), proteins from Geobacillus thermodenitrificans DSM465 for vapor permeation (Yoshikawa et al., 2004b) and molecular recognition (Yoshikawa et al., 2006, 2007a), DNA for gas (Matsuura et al., 2006) and chiral separation (Yoshikawa et al., 2007b, 2007c; Iwamoto et al., 2009), chitosan for chiral (Iwamoto et al., 2010a) and vapor permeation (Iwamoto et al., 2010b), optical 
resolution with molecularly imprinted nanofiber membranes from cellulose acetate (Sueyoshi et al., 2010), and keratin for optical resolution (Sueyoshi et al., 2011).

Chitin, which is an abundant green polymer on the earth and is main component of exoskeletons of arthropods, such as crustaceans and insects, is one of promising green polymers as a membrane material. Chitin is a polymer of $\mathrm{N}$-acetyl glucosamine and containing chiral environment, which is expected to discriminate absolute configuration of a given mixture of enantiomers. One of the authors has recently isolated chitin nanofibers from the exoskeletons of crabs and shrimps (Ifuku et al., 2009, 2010). The obtained chitin nanofibers have a highly uniform structure of 10-20 nm in width and a high aspect ratio. Furthermore, as chitin nanofibers consist of an antiparallel extended crystalline structure, they have excellent mechanical properties, including a high Young's modulus, high fracture strength and low thermal expansion. Given their characteristic nano-form and excellent physical properties, chitin nanofibers are strong candidates for a membrane for chiral separation. To this end, chitin nanofiber membranes were fabricated and their chiral separation ability was studied adopting racemic mixture of amino acids as model racemates.

\section{Experimental Section}

\subsection{Materials}

Chitin powder from crab shells was purchased from Nacalai Tesque. D-Glutamic acid (D-Glu), L-glutamic acid (L-GLu), D-phenylalanine (D-Phe), L-phenylalanine (L-Phe), D-lysine (D-Lys), and L-lysine (L-Lys) were used as received. Water purified with an ultrapure water system (Simpli Lab, Millipores S. A., Molsheim, France) was used.

\subsection{Membrane Preparation}

Chitin nanofibers were prepared from commercially available chitin powder derived from crab shells according to a previously described procedure (Ifuku et al., 2010). Fibrillated chitin nanofibers were dispersed in water at a fiber content of $0.1 \mathrm{wt} \%$. The suspension was vacuum-filtered using a hydrophilic polytetrafluoroethylene membrane filter (Millipore, pore size: $0.2 \mathrm{~mm}$ ). The obtained chitin nanofiber membrane was hot-pressed at $100{ }^{\circ} \mathrm{C}$ for $30 \mathrm{~min}$ to obtain a dried sheet. The thickness of the chitin nanofiber membrane thus obtained was determined to be $85 \mu \mathrm{m}$.

\subsection{Enantioselective Transport}

A membrane (area, $3.0 \mathrm{~cm}^{2}$ ) was fixed tightly between two chambers of a permeation cell. The volume of each chamber was $40.0 \mathrm{~cm}^{3}$. An aqueous solution of racemic mixture of amino acid was placed in the left-hand side chamber and an aqueous solution in the right-hand side chamber. Each concentration of racemic amino acid was fixed to be $1.0 \times 10^{-3} \mathrm{~mol} \mathrm{dm}^{-3}$. All experiments were carried out at $40{ }^{\circ} \mathrm{C}$. The amounts of the $\mathrm{D}-$ and L-isomers that transported through the membrane were determined by liquid chromatography (LC) [JASCO PU 1580, equipped with a UV detector (JASCO 1570)] employing a CHIRALPAK MA (+) column $(50 \mathrm{~mm} \times 4.6 \mathrm{~mm}$ (i.d.)) (Daicel Chemical Ind. Ltd.) for the analyses of racemic Glu's and Phe's, and a CROWNPAK CR (+) column ( 150 x $4.0 \mathrm{~mm}$ (i.d.)) for the measurement of racemic Lys's. An aqueous copper sulfate solution was used as a mobile phase for Glu and Phe analyses, and a perchloric acid solution as eluent for Lys analysis.

The flux, $J\left(\mathrm{~mol} \mathrm{~cm} \mathrm{~cm}{ }^{-2} \mathrm{~h}^{-1}\right)$, is defined as:

$$
J=Q \delta / A t
$$

where $Q(\mathrm{~mol})$ denotes the amount of transported amino acid, $\delta(\mathrm{cm})$ membrane thickness, $A\left(\mathrm{~cm}^{2}\right)$ the membrane area, and $t(\mathrm{~h})$ is the time.

The permselectivity, $\alpha_{\mathrm{i} j \mathrm{j}}$, is defined as the flux ratio, $J_{\mathrm{i}} / J_{\mathrm{j}}$, divided by the concentration ratio ([i-AA]/[j-AA]):

$$
\alpha_{\mathrm{i} / \mathrm{j}}=\left(J_{\mathrm{i}} / J_{\mathrm{j}}\right) /([\mathrm{i}-\mathrm{AA}] /[\mathrm{j}-\mathrm{AA}])
$$

The subscripts D and L refer to the D-isomer of amino acid and the L-isomer of amino acid, respectively.

\subsection{Adsorption Selectivity}

The membrane was immersed in a $1.0 \times 10^{-3} \mathrm{~mol} \mathrm{dm}^{-3}$ racemic amino acid solution and the mixture was allowed to equilibrate at $40{ }^{\circ} \mathrm{C}$. A $0.02 \mathrm{wt}$ \% sodium azide was added as a fungicide. The amount of amino acid in the supernatant subtracted from the amount initially in the solution gave the amount of the amino acid adsorbed by the membrane. Quantitative analyses were done as above.

Adsorption selectivity, $S_{\mathrm{A}(\mathrm{i} j \mathrm{j})}$, is defined as

$$
S_{\mathrm{A}(\mathrm{i} j \mathrm{j})}=((\mathrm{i}-\mathrm{AA}) /(\mathrm{j}-\mathrm{AA})) /([\mathrm{i}-\mathrm{AA}] /[\mathrm{j}-\mathrm{AA}])
$$


where (i-AA) and (j-AA) denote the amount of enantiomer of amino acid adsorbed in the membrane, and [i-AA] and $[\mathrm{j}-\mathrm{AA}]$ are the concentrations in the solution after equilibrium had been reached, respectively.

\section{Results and Discussion}

Three types of racemic amino acid were adopted as model racemates. Among nineteen types of amino acid, racemic glutamic acids (Glu's) with very polar anionic side chains, racemic phenylalanine (Phe's) having aromatic side chain, and racemic lysine (Lys's) with very polar cationic side chains, were adopted as model racemates in the present study.

Concentration gradient was adopted as a driving force for membrane transport of above amino acids. As an example, time-transport curves of racemic mixture of three types of amino acid are shown in Figure 1. The D-isomer of Phe was transported in preference to the corresponding L-isomer. The permeselectivity toward D-Phe was determined to be 1.16. As for other amino acids, such as Glu and Lys, the D-isomer was preferentially transported through the present chitin nanofiber membrane like Phe. The permselectivies were determined to be 1.04 for racemic Glu's and 1.07 for racemic Lys's, respectively. The permselectivities for the present chitin nanofiber membranes were not so high comparing with membrane performances previously reported (Maier. et al., 2007; Xie et al., 2008; Higuchi et al., 2010).

Adsorption selectivities of those membranes toward three types of racemic amino acid were studied so that the mechanism for the expression of permselectivities could be elucidated. In Table 1, the amounts of amino acids adsorbed in the membrane and adsorption selectivities are given. The L-isomers of Glu and Phe were incorporated into the membrane in preference to the corresponding antipodes, while D-Lys was selectively adsorbed in the membrane. Especially, the adsorption selectivity toward L-Phe reached 2.33. From permselectivity and adsorption selectivity, diffusivity selectivity, $S_{\mathrm{D}(\mathrm{i} j \mathrm{j})}$, can be determined by equation (4).

$$
S_{\mathrm{D}(\mathrm{i} j \mathrm{j})}=\alpha_{\mathrm{ij}} / S_{\mathrm{A}(\mathrm{i} j \mathrm{j})}\left(=D_{\mathrm{i}} / D_{\mathrm{j}}\right)
$$

where $D_{\mathrm{i}}$ and $D_{\mathrm{j}}$ are diffusion coefficients of i-isomer and j-isomer, respectively. The diffusivity selectivities for those three types of amino acid are summarized in Table 2 together with flux values and other selectivities, such as permselectivity and adsorption selectivity. As for the transport phenomena of Glu and Phe, the enantiomer, which was less incorporated into the membrane, was quickly diffused within the membrane. In other words, the diffusivity of enantiomer preferentially adsorbed in the membrane was retarded. This retarded diffusion might be due to a relatively strong interaction between the enantiomer selectively adsorbed and the membrane as often observed in chiral separation (Yoshikawa et al., 2003, 2007c; Masawaki et al., 1992; Aoki et al., 1995; Tone et al. 1996). On the other hand, the diffusivity selectivity for Lys gave same tendency like adsorption selectivity even though the value of selectivity was not so high.

From the intercept of the steady-state portion of time-transport curve in Figure 1, the time lag, for a given enantiomer is determined (Mulder, M., 1996). Using those time lags, diffusivity selectivity can be estimated by equation (5).

$$
S_{\mathrm{D}(\mathrm{i} / \mathrm{j})}=\theta_{\mathrm{j}} / \theta_{\mathrm{i}}
$$

As can be seen in Figure 1, the time lag for the D-isomer was shorter than that for the L-isomer. This leads to the conclusion that the diffusion coefficient for D-amino acid was higher than that for the corresponding L-isomer. As a result, it was qualitatively concluded that the diffusivity selectivity toward D-amino acid was over unity. It was revealed that the D-isomer diffused within the membrane faster than the L-isomer. The diffusivity selectivity qualitatively elucidated from time lag data coincided with that determined from permselectivity and adsorption selectivity.

In our previous study of enantioselective transport of racemic amino acids through molecularly imprinted membranes (Yoshikawa et al., 2003), applying an optimum potential difference as the driving force, the permselectivity, reflecting adsorption selectivity, was attained. In other words, applying enantioselective electrodialysis, permselectivity, which corresponds to the adsorption selectivity, was attained. In the present study on optical resolution of racemic Phe's, additional potential difference was applied by electrodialysis to obtain permselevctivity, reflecting adsorption selectivity. Against expectation, permselectivity was hardly observed. This might be due to the fact that enantiomers non-specifically dragged by applied potential difference diffused through the mesh between chitin nanofiber, which was still too large to express permselectivity. Narrowing mesh size between chitin nanofibers or plugging the mesh with some polymeric materials would enhance permselectivity. 


\section{Conclusions}

Nanofiber membranes for chiral separation were prepared from chitin, which is the most abundant natural amino polysaccharide. The membrane showed chiral separation ability by adopting concentration gradient as a driving force for membrane transport. In other words, the chitin nanofiber membrane transported the D-isomer of glutamic acid (Glu), phenylalanine (Phe), and lysine (Lys) from the corresponding racemic amino acid mixtures faster than the corresponding L-isomer.

\section{References}

Aoki, T., Tomizawa, S., \& Oikawa, E. (1995). Enantioselective permeation through poly $\{-[3-[$ pentamethyldisiloxanyl]propyl]-L-glutamate $\} \quad$ membranes. $\quad J . \quad M e m b r . \quad S c i ., \quad 99, \quad 117-125$. http://dx.doi.org/10.1016/0376-7388(94)00199-9

Higuchi, A., Tamai, M., Ko, Y.-A., Tagawa, Y., Wu, Y.-H., Freeman, B. D., Bing, J.-T., Chang, Y., \& Ling, Q.-D. (2010). Polymeric membranes for chiral separation of pharmaceuticals and chemicals. Polym. Rev. 50, 113-143. http://dx.doi.org/10.1080/15583721003698853

Ifuku, S., Nogi, M., Abe, K., Yoshioka, M., Morimoto, M., Saimoto, H., \& Yano, H. (2009). Preparation of chitin nanofibers with a uniform width as $\alpha$-chitin from crab shells. Biomacromolecules, 10, 1584-1588. http://dx.doi.org/10.1021/bm900163d

Ifuku, S., Nogi, M., Yoshioka, M., Morimoto, M., Yano, H., \& Saimoto, H. (2010). Fibrillation of dried chitin into 10-20 nm nanofibers by a simple method under acidic conditions. Carbohydrate Polymers, 81, 134-139. http://dx.doi.org/10.1016/j.carbpol.2010.02.006

Iwamoto, Y., Maruhahsi, M., Yoshiakwa, M., \& Ogata, N. (2009). Chiral separation with photo-cured DNA-(4-vinylbenzyltrimethylammonium) complex membranes. Membrane, 34, 281-287.

Iwamoto, Y., Yoshikawa, M., Yamaoka, K., \& Ogata, N. (2010a). Optical resolution with membranes derived from marine polymers. Desalination Water Treatment, 17, 268-274. http://dx.doi.org/10.5004/dwt.2010.1728

Iwamoto, Y., Shimizu T. Murai, Y., Yoshikawa, M., \& Ogata, N. (2010b). Vapor permeation of bioethanol with quaterinized chitosan-lipid complex membranes. Membrane, 35, 201-204.

Izumi, J., Yoshikawa, M., \& Kitao, T. (1997). Enantioselective permeation of racemic glutamic acid through alternative molecularly imprinted cellulose acetate membranes. Membrane, 22, 149-154. http://dx.doi.org/10.5360/membrane.22.149

Kondo, Y., \& Yoshikawa, M. (2001). Egg shell membranes for chiral separation. Membrane, 26, 228-230. http://dx.doi.org/10.5360/membrane.26.228

Maier, N. M., \& Lindner, W. (2007). Chiral recognition applications of molecularly imprinted polymers: a critical review. Anal. Bioanal. Chem.., 389, 377-397. http://dx.doi.org/10.1007/s00216-007-1427-4

Masawaki, T., Sasai, M., \& Tione, S. (1992). Optical resolution of amino acid by an enantioselective ultrafiltration membrane. J. Chem. Eng. Jpn., 25, 33-39. http://dx.doi.org/10.1252/jcej.25.33

Matsuura, T., Sada, T., Yoshikawa, M., \& Ogata, N. (2006). Oxygen permselective membranes from DNA-lipid complexes. Membrane, 31, 281-283.

McKee, T., \& McKee, J. R. (2003). The molecular basis of life. (3rd ed.). Boston: WCB/McGraw-Hill.

Mulder, M. (1996). Basic principles of membrane technology. (2nd ed.). Dordrecht: Kluwer Academic Publishers. http://dx.doi.org/10.1007/978-94-009-1766-8

Sueyoshi, Y., Fukushima, C., \& Yoshikawa, M. (2010). Molecularly imprinted nanofiber membranes from cellulose acetate aimed for chiral separation. J. Membr. Sci., 357, 90-97. http://dx.doi.org/10.1016/j.memsci.2010.04.005

Sueyoshi, Y., Hashimoto, T., Yoshikawa, M., \& Watanabe, K. (2011). Transformation of intact chicken feathers into chiral separation membranes. Waste Biomass Valor, 2, 303-307. http://dx.doi.org/10.1007/s12649-011-9066-6

Tone, S., Masawaki, T., \& Eguchi, K. (1996). The optical resolution of amino acids by plasma polymerizaed terpene membrtanes. J. Membr. Sci., 118, 31-40. http://dx.doi.org/10.1016/0376-7388(96)00071-3

Voet, D., \& Voet, J. G. (1990). Biochemistry. New York: Wiley.

Xie, R., Chu, L.-L., \& Deng, J.-G. (2008). Membranes and membrane processes for chiral resolution. Chem. Soc. 
Rev. 37, 1243-1263. http://dx.doi.org/10.1039/b713350b

Yoshiakwa, M., Ooi, T., \& Izumi, J. (1999). Alternative molecularly imprinted membranes from a derivative of natural polymer, cellulose acetate. J. Appl. Polym. Sci., 72, 493-499. http://dx.doi.org/10.1002/(SICI)1097-4628(19990425)72:4<493::AID-APP5>3.0.CO;2-U

Yoshikawa, M., Yoshioka, T., Fujime, J., \& Murakami, A. (2000). Pervaporation separation of MeOH/MTBE through agarose membranes. J. Membr. Sci., 178, 75-78. http://dx.doi.org/10.1016/S0376-7388(00)00478-6

Yoshikawa, M., Masaki, K., \& Ishikawa, M. (2002). Pervaporation separation of aqueous organic mixtures through agarose membranes. J. Membr. Sci., 205, 293-300. http://dx.doi.org/10.1016/S0376-7388(02)00131-X

Yoshikawa, M., \& Izumi, J. (2003). Chiral recognition sites converted from tetrapeptide derivatives adopting racemates as print molecules. Macromol. Biosci., 3, 487-498. http://dx.doi.org/10.1002/mabi.200350016

Yoshikawa, M., Higuchi, A., Ishikawa, M., Guiver, M. D., \& Robertson, G. P. (2004a). Vapor permeation of aqueous 2-propanol solutions through gelatin/Torlon poly(amide-imide) blended membranes. J. Membr. Sci., 243, 89-95. http://dx.doi.org/10.1016/j.memsci.2004.05.033

Yoshikawa, M., Kawamura, K. Ejima, A. Aoki, T., Watanabe, K., Guiver, M. D., \& Robertson, G. P. (2004b). Thermostable natural protein polymers from Geobacillus thermodenitrificans DSM465 as membrane materials for vapor permeation. Membrane, 29, 384-387. http://dx.doi.org/10.5360/membrane.29.384

Yoshikawa, M., Kawamura, J., Ejima, A., Aoki, T., Sakurai, S., Hayashi, K., \& Waranabe, K., (2006). Green polymers from Geobacillus thermodenitrificans DSM465 - candidates for molecularly imprinted materials. Macromol. Biosci., 6, 210-215. http://dx.doi.org/10.1002/mabi.200500187

Yoshikawa, M., Kawamura, K., \& Watanabe, K. (2007a). Evaluation of the recognition ability of molecularly imprinted proteins by surface Plasmon resomnance (SPR) sopectroscopy. Membrane, 32, 40-44.

Yoshikawa, M., Maruhashi, M., Iwamoto, Y., \& Ogata, N. (2007b). Chiral separation of racemic amino acids through DNA-polydiallyldemithylammonium polyion complex membranes. Macromol. Symp., 249-250, 557-561. http://dx.doi.org/10.1002/masy.200750436

Yoshikawa, M., Maruhashi, M., Iwamoto, Y., \& Ogata, N. (2007c). Optical resolution of racemic amino avids through DNA-poly(4-vinylbenzyl)triethylammonium polyion complex membranes. Polym. J., 39, 1193-1198. http://dx.doi.org/10.1295/polymj.PJ2007080

Table 1. Adsorption of racemic mixture of amino acids in chitin nanofiber membrane

\begin{tabular}{ccccc}
\hline \multirow{2}{*}{ Amino Acid } & \multicolumn{2}{c}{ (Amino Acid) $/$ mem. } & $S_{\mathrm{A}(\mathrm{D} / \mathrm{L})}$ & $\mathrm{S}_{\mathrm{A}(\mathrm{L} / \mathrm{D})}$ \\
\cline { 2 - 5 } & $10^{5} \mathrm{~mol} / \mathrm{g}$-mem. & $10^{3} \mathrm{~mol} / \mathrm{CRU}^{\mathrm{a}}$ & & \\
\hline D-Glu & 5.18 & 9.27 & 0.96 & \multirow{2}{*}{1.04} \\
L-Glu & 5.41 & 9.68 & & \\
D-Phe & 1.57 & 2.81 & 0.43 & 2.33 \\
L-Phe & 3.66 & 6.55 & & \\
D-Lys & 3.01 & 5.38 & 1.04 & 0.96 \\
L-Lys & 2.90 & 5.18 & & \\
\hline
\end{tabular}

${ }^{\text {a }}$ Constitutional repeating unit of chitin.

Table 2. Results of chiral separation with chitin nanofiber membrane ${ }^{\mathrm{a}}$

\begin{tabular}{|c|c|c|c|c|c|}
\hline Amino Acid & 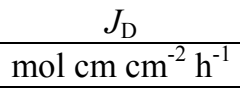 & 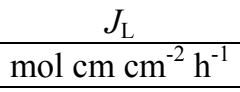 & $\begin{array}{r}\alpha_{\mathrm{D} / \mathrm{L}} \\
\left.\alpha_{\mathrm{L} / \mathrm{D}}\right) \\
\end{array}$ & $\begin{array}{c}S_{\mathrm{A}(\mathrm{D} / \mathrm{L})} \\
\left(S_{\mathrm{A}(\mathrm{L} / \mathrm{D})}\right)\end{array}$ & $\begin{array}{c}S_{\mathrm{D}(\mathrm{D} / \mathrm{L})} \\
\left(S_{\mathrm{D}(\mathrm{L} / \mathrm{D})}\right)\end{array}$ \\
\hline Glu & $7.93 \times 10^{-10}$ & $7.59 \times 10^{-10}$ & $\begin{array}{c}1.04 \\
(0.96)\end{array}$ & $\begin{array}{c}0.96 \\
(1.04)\end{array}$ & $\begin{array}{c}1.08 \\
(0.92)\end{array}$ \\
\hline Phe & $1.25 \times 10^{-9}$ & $1.08 \times 10^{-9}$ & $\begin{array}{c}1.16 \\
(0.86)\end{array}$ & $\begin{array}{c}0.43 \\
(2.33)\end{array}$ & $\begin{array}{c}2.70 \\
(0.37)\end{array}$ \\
\hline Lys & $1.18 \times 10^{-9}$ & $1.10 \times 10^{-9}$ & $\begin{array}{c}1.07 \\
(0.93)\end{array}$ & $\begin{array}{c}1.04 \\
(0.96)\end{array}$ & $\begin{array}{c}1.03 \\
(0.97)\end{array}$ \\
\hline
\end{tabular}

${ }^{\mathrm{a}} \alpha_{\mathrm{i} / \mathrm{j}}=S_{\mathrm{D}(\mathrm{i} / \mathrm{j})} \times S_{\mathrm{A}(\mathrm{i} / \mathrm{j})}[\mathrm{i}=\mathrm{D}, \mathrm{j}=\mathrm{L}$ or $\mathrm{i}=\mathrm{L}, \mathrm{j}=\mathrm{D}]$ 
(a)

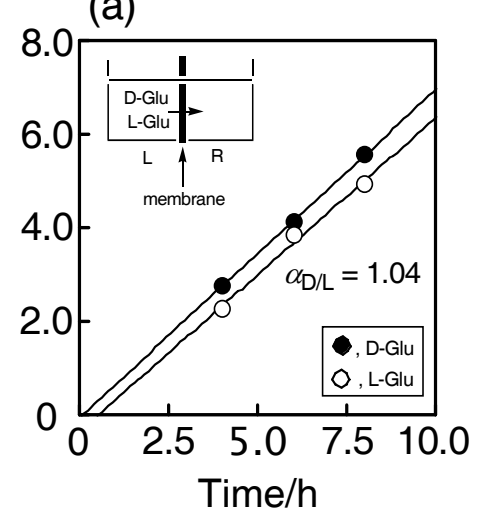

(b)

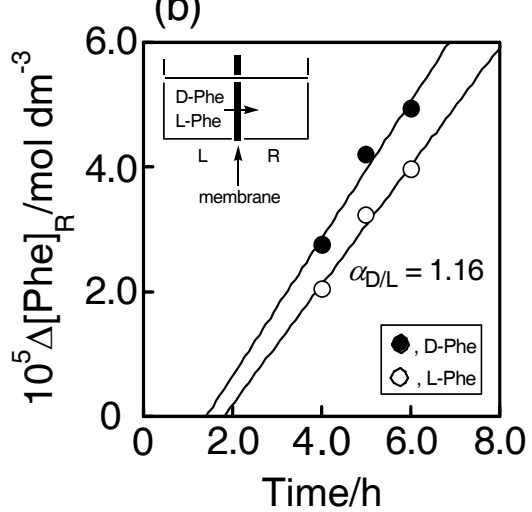

(c)

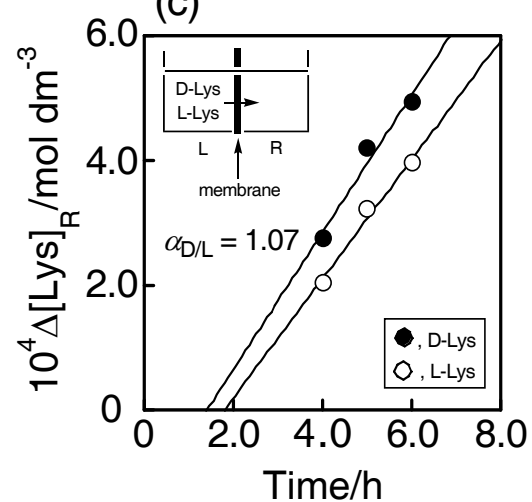

Figure 1. Time-transport curves of racemic mixtures of Glu's (a), Phe's (b), and Lys's (c) through the chitin nanofiber membrane at $40{ }^{\circ} \mathrm{C}$

$$
\left([\mathrm{D}-\mathrm{AA}]_{0}=[\mathrm{L}-\mathrm{AA}]_{0}=1.0 \times 10^{-3} \mathrm{~mol} \mathrm{dm}^{-3} ; \mathrm{AA}: \text { Glu, Phe, or Lys. }\right)
$$

